\title{
International seminar on "Is access enough? Understanding and addressing unmet need for family planning"
}

IUSSP Scientific Panel on Reproductive Health

Follow this and additional works at: https://knowledgecommons.popcouncil.org/departments_sbsr-rh

Part of the Demography, Population, and Ecology Commons, Family, Life Course, and Society Commons, International Public Health Commons, Maternal and Child Health Commons, and the Women's Health Commons How does access to this work benefit you? Let us know!

\section{Recommended Citation}

"International seminar on Is access enough? Understanding and addressing unmet need for family planning," STEP UP Seminar Report. 


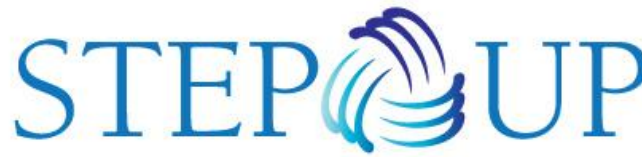

STRENGTHENING EVIDENCE FOR PROGRAMMING ON UNINTENDED PREGNANCY

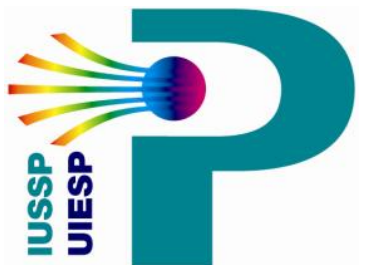

International Seminar on

Is access enough? Understanding and addressing unmet need for Family Planning

14-17 May 2013

Nanyuki, Kenya

Organized by the International Union for the Scientific Study of Population (IUSSP)

Scientific Panel on Reproductive Health

and

Strengthening Evidence for Programming on Unintended Pregnancy (STEP UP) Consortium and

African Institute for Development Policy (AFIDEP)

\section{Seminar Report}

The IUSSP Scientific Panel on Reproductive Health, in collaboration with STEP UP Consortium and AFIDEP held a seminar on "Is access enough? Understanding and addressing unmet need for Family Planning" in Nanyuki, Kenya, 14-17 May 2013. Financial support for seminar was provided by the US Agency for International Development (USAID); the Wellcome Trust; and the World Health Organization's Department of Reproductive Health and Research (WHO/RHR). Despite the prominence of unmet need as an indicator for monitoring progress in MDG 5 to improve maternal health, and the focus of the July 2012 London Family Planning Summit on access to family planning services as being the major constraint to reducing global unmet need, there is still vigorous debate about its definition, measurement, use as a programme indicator, and utility as a guide for programme interventions.

Twenty-five papers were presented, including one paper that systematically reviewed the evidence on unmet need and its causes and one paper reviewing the evidence on unintended pregnancy. The remaining 23 papers were divided among five different sessions: Unmet need: definition and measurement; Unmet need and fertility decline; Reasons for unmet need; Special groups with unmet need; and Reducing unmet need: policy and programme interventions. The papers ranged from global and national level analyses to community level studies. Papers are available to IUSSP members at http://www.iussp.org/en/event/19/programme, and the agenda and list of participants are included in the appendices.

Women in developing countries who either want no more children or do not want a child in the next two years but are not using any method of contraception are defined as having an unmet need for contraception. Most broadly put, family planning programmes are intended to facilitate contraceptive adoption by non-users with unmet need and to encourage continuation of use or prompt switching to another method in case of discontinuation among current users. But programmes' success in facilitating contraceptive adoption and continuation depends on how well they address the whole range of factors that tend to place women at elevated risk of unmet need. A disaggregated and in-depth analysis of unmet need can guide the development of policies and programmes specifically designed to reach women with unmet need. Illustratively, 
young married or unmarried sexually active women and men, postpartum women, and women who have recently discontinued use of contraception or have had an abortion may be at high risk of unmet need for reasons that differ from one subgroup to the next and from one setting to the next.

This seminar brought together 44 scientists, policy makers, and programme managers to present and discuss a range of issues relating to the definition, determinants and consequences of unmet need for family planning and programme interventions designed specifically to reduce unmet need in groups at high risk.

Specific issues that were addressed included:

- Unmet need - the concept, interpretation, and relevance to programmes, unmet need vs. demand;

- Measurement issues relating to unmet need;

- Levels, trends and differentials: across regions, countries, subpopulations, socioeconomic (SES) groups, marital and age groups;

- Reasons for unmet need - programmatic, psychological, social (including spouses and other persons), health concerns, past reproductive experience (including contraceptive use), etc.;

- The impact of programmatic interventions specifically designed to address unmet need;

- Unmet need as a determinant of unintended pregnancy;

- The relationship of unmet need for limitation and spacing/postponement to fertility decline, including birth interval analysis.

\section{Highlights and findings}

\section{Unmet need and its causes}

The seminar began with an overview of unmet need, which highlighted the central role the concept of unmet need has in the discourse on population and development (Casterline and Layton). This paper provided an overview of the history of the concept of unmet need, the development and refinement of methods of its empirical measurement, and the causes of unmet need. The paper surmised that four main priorities deserve further attention: 1) the lack of clarity about contraceptive goals partly because unmet need assumes the goal of contraception by all women who do not want a child. Because of this assumption the current algorithm measuring unmet need assumes who needs to be protected and therefore excludes women who want a child in the next 2 years and women who are infecund. Authors note that if the goal is the prevention of unintended pregnancy through perfect contraceptive coverage, more discussion is needed on this topic; 2) Limited research on the causes of unmet need, partly because the current measurement from the DHS has serious design and information limitations. More in-depth research is therefore needed to capture the causes which vary across and within society; 3) Calls for research on unmarried women is largely unanswered, possibly because of the Millennium Development Goal's addition of unmet need among women in union may have diminished the enthusiasm for research on unmet need among unmarried women; 4) Unmet need is the outcome of clusters of decisions, including but not limited to choice of sexual partner, 
patterns of sexual activity, health service utilization etc. Incorporating advances in decisionmaking science will make for a more rounded approach to understanding unmet need as it will capture these decisions from the "standpoint of the women/couples who have made them as determined by their perceptions, the decision-making rules they apply, and the set of constraints under which they operate."

\section{Contraceptive Use and Unmet need in Kenya}

An overview of contraceptive use and unmet need for FP in Kenya was presented by Dr. Bashir, Director of Reproductive Health, Ministry of Health, Kenya. Dr. Bashir noted that family planning (FP) is regarded as a center piece for realizing the MDGs, as well as Kenya's vision 2030 goals. Levels of unmet need vary and are highest among women living in rural areas, from poor households, and among youth and persons living with HIV/AIDS. Though having a very strong FP programme in the $70 \mathrm{~s}$ and most of the $80 \mathrm{~s}$, the last decade or so has seen a weakened national FP programme. Kenya's government has as goals to reduce unmet need and increase contraceptive prevalence rate (CPR) to $56 \%$ in 2015. This will be achieved using various mechanisms: addressing the issues relating to commodity security, improving FP service provision especially in hard-to-reach areas including urban slums and rural areas, and reducing the challenges relating to human resources. Moreover, the presentation noted a heavy reliance on injectables by Kenyan women, which creates a challenge to sustainability. There needs to be provision of a wider range of methods and advocacy to increase use of long acting methods. Ultimately, uptake of FP service including effective methods will require improving and increasing male involvement.

\section{Regional differences}

Several studies looked at regional trends and national level patterns of unmet need and unintended pregnancies and noted differences across regions: regional variations in levels of unintended pregnancy were observed, with Middle and Western African countries showing lower reductions. Similarly, Middle Africa, Western Africa, Melanesia, Micronesia, and Polynesia are projected to have levels of unmet need in 2030 similar to levels of 2010. Moreover, estimated levels of unmet need exceeded contraceptive prevalence in 2010 in Middle and Western Africa, thus demand satisfied was below $50 \%$.

\section{Interesting Relationships}

Several interesting relationships were presented at the seminar. Several studies observed that unmet need and unintended pregnancy do not disappear in low fertility populations. Another study found a positive association between contraceptive prevalence and unintended pregnancy. Specifically, it was noted that though two-thirds of pregnancies occur while women use no method, about $21 \%$ of pregnancies occur while women are using modern methods. It is possible that even in settings with low levels of unmet need and increased levels of contraceptive use, method failure, ineffective and inconsistent use remain significant reasons for unintended pregnancies.

It was also noted that unmet need and fertility do not track closely, disproving the assumption that unmet need will follow patterns of fertility transition. Specifically, Casterline and El-Zeini found that in Africa, less than $10 \%$ of change in fertility can be attributed to contraceptive use. In other words, unmet need is not predictive of total fertility rate (TFR). In developed countries about three-quarters of the fertility decline have been due to declines in conditional wanted and unwanted fertility rates (improved birth control). Overall, fertility 
decline is largely, but not entirely, the consequence of increased implementation in contraceptive practice, in the context of fairly stable fertility preferences. In sub-Saharan Africa changes in unmet need and fertility do no not track each other. Interestingly, declines in wanted and unwanted fertility rates have made less contribution to fertility decline in Africa than elsewhere, and in turn these two contributions are less a function of increases in contraception than is the case in other regions. Overall, less than $10 \%$ of reduction in fertility decline is attributed to contraceptive use (Casterline and El-Zeini).

Similarly, a study by Adetunji explored the relationship between unmet need for contraception and unintended pregnancy. Premised on the concept that fecund women with prolonged unmet need for contraception will eventually have unintended pregnancies and births, the study compares and contrasts levels and trends in unmet need with unintended childbearing in nine countries. The study further assessed whether this relationship varies under different fertility regimes. Results indicate that unmet need and unintended childbearing tend to follow the same trend, but levels often differ. Connections exist between the two, though not as strong as often assumed. Unmet need and unintended childbearing do not disappear even in extremely low fertility populations. Adetunji concludes that unintended pregnancy is the face of unmet need.

Another interesting relationship presented was the impact of supply-side factors on fertility behaviour. Drawing on two major interruptions to public supply of contraceptives in the Philippines, a study by J. M. Salas explored the influence of subsidized contraceptives on fertility behaviour. Salas noted in his study that interruption to commodity donations by international aid agencies and irregularity in shipments of contraceptive commodities to various provinces in the Philippines had an effect on birth rates. Specifically, findings show a negative relationship between changes in fertility and changes in free contraception i.e. reductions in supply of free contraceptives was associated with increases in birth rates (ranged from 2.0 to 3.6 additional births per 1,000 women/per year). Similarly, irregularities in public supply resulted in a $6 \%$ increase in birth rates (range from 0.5 to 1.1 additional births per 1,000 women), indicating fertility was sensitive to changes in contraceptive supply levels. Finally, supply fluctuations resulted in a rebound in use of traditional methods, while the most disadvantaged groups (including rural residents, less educated and the poor) presented higher pregnancy risk due to changes in contraceptive coverage.

\section{General findings}

Structural factors including poverty and low SES were found to be key determinants of high levels of unmet in developing countries, with examples given from India (Khan \& Hazra). Many studies observed that infrequent sex and health concerns are major reported reasons for non-contraceptive use (Kazuyo \& Cleland; Sedgh et al.). Discussions around reasons for unmet need centered on the fact that we do not know among women who are using, if they are experiencing the same side effects as those who have discontinued. Moreover, there are communities where the decision making is not with the women. Therefore the differences between the husband and wife's fertility choices have significant impact on non-use of contraceptives among women. Finally there is the issue of co-residence, with many women reporting a partner living outside of the home (especially among the educated) and therefore infrequent sex as the major reason for non-contraceptive use among women in union.

A paper by Hagey et al. applied longitudinal techniques using DHS calendar data to give a different picture - termed the 'revolving door' - to capture the variable nature of unmet need. 
Using contraceptive calendars from DHS, the authors of the paper explored longitudinally the changes that unmet need goes through, by looking at the number of episodes women are experiencing. Overall, younger women are more likely to experience unmet need, while older women are more likely to experience longer episodes of unmet need. The study concludes that unmet need is a state of flux, and passes through many phases as women move in and out. Crosssectional data compared to longitudinal data may therefore be masking the magnitude of the problem. Discussions noted that rather than masking, cross-sectional data may be giving a different measure and picture.

Several studies raised the possibility that excluding and discounting natural methods as is the norm in most studies on unmet need might be problematic. Rossier et al. note that natural methods could count as a method of choice for many because of the perception that it is safer and will help women overcome certain barriers impeding contraceptive use. What is currently termed unmet need might therefore just be underreported natural method use, so more focus should be paid to natural methods. Discussions noted that currently there still are issues with counseling and correct use of modern methods, so the focus on traditional methods may still be premature.

In an overview of the bigger picture of unmet need and unintended pregnancy, it was noted that research on unintended pregnancy remains pertinent because it has significant policy and programmatic implications. There has overall been a substantial decrease in unintended pregnancy but not in intended pregnancy, which from a policy perspective is a measure of success. Most importantly, with regards to adverse outcomes of unintended pregnancy, there is documented research on abortions and miscarriages; the missing gap is the adverse outcome of unplanned births, and therefore an evidence gap that needs more investigation (Askew).

Several intervention studies were presented. Using both panel and cross-sectional data, Jain et al. assessed the effect of two strategies - elimination of unmet need and elimination of unwanted fertility among those with 'met need' for contraception on the reduction of unwanted fertility in Pakistan. According to Jain et al., using both methodologies is important as they complement each other: retrospectively, measuring unintended pregnancy is limited by changes in fertility desires. On the other hand prospective measurement of unintended pregnancy is limited by post factor rationalization. This study notes that association between unmet need and unwanted fertility is depended on the magnitude of unwanted fertility among women with met need. Understanding women with met need especially patterns of discontinuation, failure and switching, is of the essence. Overall, the authors note that supporting women with met need is important and has implications for reducing not only subsequent unmet need, but also overall unwanted fertility. How FP programmes address these women is therefore the key; in other words, how the gap between discontinuation and switching is managed is of prime importance.

Consistently, the notion of ambivalence towards childbearing, i.e. the strength of motivation to prevent a pregnancy, was noted as one of the key contributors to unintended pregnancy and unmet need. Rossier et al. in a study on urban Burkina Faso noted that poor or less educated women in urban areas want large families even though the cost of raising children in an urban context is high. This fertility desire for large families was reportedly a coping mechanism - children were perceived as an insurance policy that could potentially get families out of poverty. This study concludes that a combination of ambivalence and poor substandard services, including poor provider-client interaction, significantly contribute to high TFR in urban Burkina Faso. 
Several studies also noted the fact that urban populations (in Kenya and Burkina Faso) increasingly are presenting worse reproductive health indicators than their counterparts in the rural areas (Kuria \& Gichugi; Rossier et al.). Termed the 'disappearing urban advantage', urban poor have limited access to services, though urban areas have better access to modern methods.

Other studies emphasized the issue of spacing and postponement (Towriss \& Timaeus; Rossier et al.). These studies point to the fact that in many urban and rural populations, spacers may become limiters because of long birth intervals.

Relatively few studies explored unmet need among young women. Examples from India and Senegal noted that young women are particularly disadvantaged in access to contraception. According to Jejeebhoy et al. many young women in India want to delay first pregnancy, but demand for contraception was largely unsatisfied, partly because of cultural norms about contraceptive use and childbearing. This study made the case for sexuality education, with authors concluding that health services should reach newly married, as well young unmarried women. Another example from Senegal looked at provider bias as a factor influencing young women's access to and use of contraception. According to Sidze et al., provider bias may be restricting access to contraception for young women in urban Senegal. The authors note that there is no national policy restriction guiding this provider behaviour toward young women, rather socio-cultural norms of providers, which contribute to bias.

On the relationship between FP programmes and reduction in fertility, Bongaarts notes that though there is a strong effect of FP on unmet need, countries with strong FP programmes still have high levels of unmet need. Effects of FP programmes are offset by levels of demand, as desired family size remains high in many African countries. For example, Africa has about $50 \%$ demand but just half of that demand is satisfied. The difference between total demand and demand met is therefore unmet need. Countries with strong FP programmes still have high levels of unmet need because of several factors including socio-cultural norms (including husband's opposition), underreporting of contraceptive use and measurement errors relating to unmet need. Overall the study, however, surmised that strong FP programmes tend to overall reduce fertility by 1.6 births per woman. Similarly, countries with strong FP programmes have lower levels of unmet need and an increase in contraceptive use by $22 \%$.

The potential impact of integration was also discussed during the seminar. Malarcher and Polis note in their study that less than half of women with unmet need have future intention to use contraception and the example of Senegal was presented. Integration has the potential to reach women with unmet need through a range of services. They note that currently there is sparse evidence on the impact of integration of family planning with other health services and therefore an evidence gap that needs to be filled.

Community-based programmes could provide an avenue to increase proximity. In an example from Tanzania, Baynes et al. explored the factors that determine unmet need for FP in three rural districts. They conclude that appropriately designed and implemented communitybased family planning programmes can succeed in this setting to tackle the prevalent desires to both space and limit births among women in the study population.

Finally, on financing of FP and RH, one study presented evidence on reproductive health vouchers in Kenya. Sachathep et al. in their study look at the impact of RH vouchers in reducing inequities in access in Kenya. They conclude that output-based aid is reaching the intended audience - poor women. Authors also note that there is a latent demand for long-acting and permanent methods (LAPM) among the poor partly because the poor were more likely to use 
LAPM for limiting, while the rich were more likely to use LAPM for spacing. In Kenya, considering that $56 \%$ of women still deliver at home and 1 in 4 have an unmet need for FP, the reproductive health voucher programme remains a vital mechanism that not only empowers women who otherwise have access to health care but cannot afford it; but also gives these women choices in terms of facilities that can properly attend to them as well as demand proper services at a facility of their choosing.

\section{Methodological Issues}

Several methodological issues were identified in papers and during the presentations and discussions. It was noted that the current measure of unmet need probably underestimates need among unmarried women, while probably overestimating levels of need among married women. According to Bradley, this measure works well at the population level, but is limited at the individual level. At the individual level, it is difficult to capture a time horizon: unmet need when? Pregnant or postpartum women? This raises the question about what level of analysis is most appropriate for the measurement of unmet need - individual or population.

Secondly, unmet need is not self-defined - a woman is not saying she has an unmet need, but rather this is assigned to her on the basis of a series of questions. The concept of unmet need is a strong and powerful tool, but one that currently fails to capture individual women's preferences. Similarly, the reported reasons for non-use are constructs that may not be adequately capturing real reasons for non-use, which presents a challenge for programming and operations research. There needs to be more research on finding innovative ways of measuring and capturing reasons for non-use of contraceptives among women.

Thirdly, issues on how the concept should be measured were discussed. The debate centered on the strengths and weaknesses of retrospective versus prospective data. It was noted that current measures are mostly from retrospective data. Prospective studies of women who are users and non-users and understanding their social and psychological profiles should be investigated more.

Fourthly, the question as to whether traditional method users should be counted as nonusers was discussed. It was noted that exclusion of traditional methods might be leading to overestimation of unmet need and lengthy episodes of unmet need could just be a reflection of underreporting of traditional method use. Exclusion of traditional methods from analyses should therefore be re-examined as they may count.

Finally, the overarching problem with the current measure is the focus on married women and the classification of women as infecund, which is problematic. Discussions centered on the notion that new algorithms should be created to capture the situation of women in specific sub-groups, rather than grouping them all into broad categories.

\section{Discussion}

Several important points were made during discussions throughout the seminar:

- It was noted that there was a focus on youth at policy level but not at service delivery level. The unspoken norms that guide provision of youth services need to be tackled.

- Community-based programing, if appropriately designed and implemented, could increase proximity to services.

- Scaling up financing mechanisms such as RH voucher programmes to reduce inequities in access is of the essence. Improving on the current structure of $\mathrm{RH}$ voucher 
programmes by including facilities such as transportation, which still prevents many who have purchased the vouchers from using them, needs to be considered.

- Because of the heavy reliance on short-term methods and a limited range of choices, scaling of LAPM and provision of a wider range of choices remains critical.

- There should be investment in demand-side interventions, while also looking at the structural factors that seem to influence high levels of unmet need.

- Most of the studies were global estimates, with some overlap. The issue with global estimates is that they have policy implications but limited programmatic implications. It was therefore important that clear linkages be made between global level, programme level (service providers), and micro level trends. How these are connected needs to be investigated more. Finally, more country level analyses will be necessary as they are needed to capture more variation. Further disaggregation even within continents and region is of importance as it will have more programmatic adaptability to inform operations research.

- It was noted that some of the regional differences could be a reflection of current differences in policy space and programme availability. The projections for Middle and Western Africa might be gloomy but the policy space and progressive intensification by governments and agencies could change that.

- What is of central concern: women's fertility intentions or TFR? In answering this question, the field could benefit from bringing in a social psychological viewpoint - a call for more qualitative studies was therefore made. A socio-psychological viewpoint will be better able to capture the point that unmet need is not a one-time event; in-depth understanding of people's decision-making process has strong programmatic implications.

- Rethinking the exclusion of traditional methods in analyses. There is a need to tease out more the profile of traditional method users and how they work in settings where women don't have much negotiating power. It was also noted that perhaps more studies on fertility awareness and fertility awareness methods will be necessary.

- It was noted that viewpoints from the male were almost non-existent. Because of the relational nature of contraceptive use, involving men in the discussion and programmes on unmet need is imperative.

- There was no mention of medical abortion. The advent of medical abortion is posited to change the merits of methods with high failure rates.

- Women are not a homogenous group and should not be treated as such. The evidence gap therefore needs to consider different groups - young people, unmarried women, urban poor and persons living with HIV/AIDS.

- Finally, more operations research is needed as well as looking in more depth into the supply side interaction with unmet need.

\section{Conclusions}

Several pertinent questions remain: How should we be thinking about access? What will be the best way to measure access? Should it be based on attitude; knowledge; physical; monetary; or social? Overall, access is multifaceted and should capture both client perspective and supply side. Estimations of unmet need using access as the barrier maybe overestimating levels of unmet need, but the fear that we may also be over-simplifying the process was mentioned. 
Is access enough to reduce unmet need? Access is necessary but not sufficient for tackling unmet need. Access is necessary because:

- Commodity insecurity remains a key determinant of access and use of contraceptive services and methods.

- Sociocultural norms act as great impediments to reducing unmet need. Similarly sociocultural disapproval including partner opposition drives non-use. Interpersonal communication between partners and understanding differences in husband's and wife's fertility choices, and how women negotiate becomes important.

- Provider-client interaction is crucial in determining women's access to services and use of commodities.

- Improving client care as well as increasing proximity through CBD programmes is necessary.

Based on discussions and presentations, unmet need (and FP in general) should be looked at both from a development perspective and from a service delivery and health sector perspective. This makes the strong case for integration, where service provision may become a one-stopshop for both women and men. Overall, the seminar papers, presentations and discussions asserted that physical access is no longer the primary barrier to addressing unmet need for family planning and that a range of other individual, community and delivery system characteristics need to be considered.

\section{Acknowledgements}

The IUSSP Panel on Reproductive Health gratefully acknowledges Joyce Mumah, the recipient of the IUSSP Junior Demographer Award, for developing this seminar report; Sarah Harbison for skillfully organizing the Seminar; STEP UP and AFIDEP for co-sponsoring it; Paul Monet for coordinating the various activities; Joyce Ombeva for providing administrative and logistical support; and USAID, the Wellcome Trust and WHO/RHR for the financial support. The Panel also acknowledges the invaluable inputs made by authors of papers, discussants, chairs of sessions and participants of the Seminar.

\section{IUSSP Scientific Panel on Reproductive Health}

Chair: Iqbal H. Shah

Members: John Cleland, Sarah Harbison, Ondina Fachel Leal, K.G. Santhya, Eliya Msiyaphazi Zulu. IUSSP Council Liaison: Shireen Jejeebhoy 
International Union for the Scientific Study of Population (IUSSP)

Scientific Panel on Reproductive Health

and

Strengthening Evidence for Programming on Unintended Pregnancy (STEP UP)

Consortium

and

African Institute for Development Policy (AFIDEP)

\section{International Seminar: Is access enough? Understanding and addressing unmet need for Family Planning}

Nanyuki, Kenya, 14-17 May 2013

\section{Meeting Agenda}

Tuesday, 14 May 2013

08:30

Session 1:

Chair:

09:00-09:30

09:30-09:40

09:40-09:45

09:45-10:00

10:00-10:20

$10: 20-10: 35$

\section{Registration}

Opening of the Seminar

John Cleland

Opening remarks

Introductions

Background and agenda

Logistics

Contraceptive use and unmet need for

family planning in Kenya

Issak Bashir

John Casterline

Sheila Macharia

Ian Askew

Eliya Zulu

Shireen Jejeebhoy

Sarah Harbison

Joyce Ombeva

Unmet need for family planning in developing countries: an overview

Coffee/tea 
Session 2:

Chair:

Discussant:

10:35-10:55

10:55-11:15

$11: 15-11: 35$

11:35-11:50

11:50-12:10

12:10-12:30

$12: 30-12: 50$

12:50-14:00

14:00-14:15

14:15-14:45

Session 3:

Chair:

Discussant:

14:45-15:05

$15: 05-15: 25$

$15: 25-15: 45$

$15: 45-16: 00$

16:00-16:15
Unmet need: definition and measurement

David Kline

John Cleland/Shireen Jejeebhoy

Unmet need and unintended pregnancy: The bigger picture

Ian Askew

Measuring unmet need with the revised definition: strengths and limitations

Sarah E.K. Bradley

Long-term trends in unmet need for family planning and contraceptive prevalence and programme implications, 1970 to 2020

Vladimira Kantorova, Ann Biddlecom, and Leontine Alkema

Discussant comments: John Cleland

Unpacking unmet need: reproductive health transitions and its consequences

Jill Hagey, Toshiko Kaneda, Rhonda Smith, and Wendy Baldwin

Changes in unmet need and its intensity over time

Elizabeth Leahy Madsen, John Ross, and Karen Hardee

Do natural methods count? Underreporting of natural contraception in urban Burkina Faso

Clémentine Rossier, Leigh Senderowicz and Abdramane Soura

\section{Lunch}

Discussant comments: Shireen Jejeebhoy

Discussion

\section{Unmet need and fertility decline}

Shireen Jejeebhoy

K.G. Santhya/Sarah Harbison

Unmet need and fertility decline: national level patterns

John B. Casterline and Laila O. el-Zeini

Unmet need for family planning and unintended childbearing under various fertility regimes

Jacob Adetunji

Unmet need and induced abortion in sub--Saharan Africa: A crossnational analysis using two different estimators of abortion

Supriya Madhavan

Coffee/Tea

Discussant comments: K.G. Santhya 
16:15-16:35 Lengthening birth intervals and unmet need for contraception in rural and urban East Africa

Catriona Towriss and Ian Timæus

16:35-16:55 Unmet need and unwanted childbearing in Pakistan: Evidence from a panel survey

Anrudh K. Jain, Arshad Mahmood, and Zeba Sathar

16:55-17:05 Discussant comments: Sarah Harbison

17:05-17:35 Discussion

19:00 Group dinner (all participants)

\section{Wednesday, 15 May}

Session 4:

Chair:

Discussant:

09:00-09:20

09:20-09:40

09:40-10:00

10:00-10:15

$10: 15-10: 35$

$10: 35-10: 55$

10:55-11:15

$11: 15-11: 25$

$11: 25-11: 55$

$11: 55-13: 30$

$13: 30-$
Reasons for unmet need

K.G. Santhya

Iqbal Shah/John Casterline

Reasons for contraceptive nonuse among women with an unmet need in developing countries: a comprehensive analysis of levels and trends Gilda Sedgh, Akinrinola Bankole, Susheela Singh, and Rubina Hussain

The determinants of women's unmet need for contraception and implications for a community-based family planning programme in three rural districts of Tanzania

Colin Baynes, Malick Kanté, Amon Exavery, Mustafa Njozi, Elizabeth F. Jackson and James F. Phillips

Unmet Need for Family Planning in Ghana: Trends and Determinants Kazuyo Machiyama and John Cleland

Discussant comments: Iqbal Shah

\section{Coffee/Tea}

Unmet need: an analysis of the level, trend and determinants of unmet need in India

M.E. Khan and Avishek Hazra

The spatial pattern and correlates of unmet need of family planning in India: Implications for programme

Ajay Singh

Discussant comments: John Casterline

Discussion

Lunch

FREE 


\section{Thursday, 16 May}

Session 5:

Chair:

Discussant:

09:00-09:20

09:20-09:40

09:40-10:00

10:00-10:15

10:15-10:45

10:45-11:30

Session 6:

Chair:

Discussant:

11:30-11:50

11:50-12:10

$12: 10-13: 30$

13:30-13:50

13:50-14:05

$14: 05-14: 25$
Special groups with unmet need

Eliya Zulu

Wendy Baldwin

Demand for contraception to delay the first pregnancy among young women in India

Shireen Jejeebhoy, K G Santhya, and A J Francis Zavier

Young women access and use of contraception: the role of providers' restrictions in urban Senegal

Estelle M. Sidze, Solène Lardoux , Ilene Speizer, Cheikh M. Faye, Mike Mutua, and Fandi Badj

The One God Sends to Save Me: Fertility Desires and Contraceptive Practices among Burkina Faso's Urban Poor

Clémentine Rossier, Leigh Senderowicz, and Abdramane Soura

Discussant comments: Wendy Baldwin

General Discussion

Coffee/Tea

Reducing unmet need: policy and programme interventions

Sarah Harbison

Eliya Zulu/Ian Askew

The impact of family planning programmes on the unmet need for contraception

John Bongaarts

Using measurements of unmet need for family planning to inform program investments for health service integration

Shawn Malarcher and Chelsea B. Polis

Lunch

Can reproductive health vouchers reduce inequities in unmet need for long acting and permanent contraceptive methods?

Karampreet Sachathep, Francis Onyango, and Benjamin Bellows

Discussant comments: Eliya Zulu

Addressing urban unmet need for family planning using behaviour change communications: Evidence from five urban areas in Kenya Paul Kuria and Debby Gachuhi 
14:25-14:45 Consequences of withdrawal: Free condoms and birth rates in the Philippines

J.M. Ian Salas

$14: 45-14: 55$

Discussant comments: Ian Askew

$14: 55-15: 25$

Discussion

$15: 25-16: 00$

Coffee/tea

\section{$\underline{\text { Friday, } 17 \text { May }}$}

$\begin{array}{ll}\begin{array}{l}\text { Session 7: } \\ \text { Chair: }\end{array} & \begin{array}{l}\text { Closing Session } \\ \text { Iqbal Shah }\end{array} \\ \text { 09:00-09:40 } & \begin{array}{l}\text { Highlights of key findings and of implications for programmes and } \\ \text { policies } \\ \text { Joyce Mumah (Junior Demographer) }\end{array} \\ \begin{array}{ll}\text { Discussion } \\ \text { 10:15-10:30 }\end{array} & \begin{array}{l}\text { Plans for publication and dissemination } \\ \text { Sarah Harbison }\end{array} \\ \text { 10:30-11:00 } & \text { Coffee/tea } \\ \text { 11:00-11:15 } & \text { Any other matter } \\ \text { 11:15-11:30 } & \text { Closing the Seminar } \\ 11: 30-13: 00 & \text { Lunch }\end{array}$

Note: For papers with more than one author, the name of the presenter is underlined. 


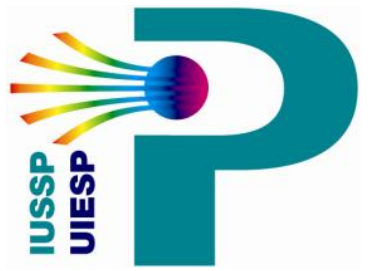

International Seminar: Is access enough?

Understanding and addressing unmet need for Family Planning

Nanyuki, Kenya 14-17 May 2013

\section{List of Participants}

\section{Jacob Adetunji}

US Agency for International Development

Office of Population and Reproductive Health

1300 Pennsylvania Ave, NW

Washington, DC 20523

United States

Email: Jadetunji@usaid.gov

\section{Moazzam Ali}

Department of Reproductive Health and Research

World Health Organization

20, avenue Appia

CH-1211 Geneva 27

Switzerland

Email: alimoa@who.int

\section{John Anampiu}

National Council for Population and Development

Chancery Building, 4th Floor, Valley Road

P.O Box 48994-00100

Nairobi

Kenya

Email: janampiu@ncpd-ke.org

\section{Ian Askew}

Reproductive Health Services and Research

Population Council

P.O. Box 17643

Nairobi 500

Kenya

Email: iaskew@popcouncil.org

\section{Wendy Baldwin}

Population Reference Bureau

1875 Connecticut Avenue, NW

Suite 520

Washington, DC 20009-5728

United States

Email: wbaldwin@prb.org
Issak Bashir

Division of Reproductive health

Department of Family Health

Ministry of Health.

Nairobi

Kenya

Email: drbashirim@yahoo.com

\section{Colin Baynes}

Columbia University/Ifakara Health Institute

PO Box 78373

Plot 463, Kiko Avenue

Mikocheni, Dar es Salaam

United Republic of Tanzania

Email: cdb2128@columbia.edu

\section{John Bongaarts}

Population Council

One Dag Hammarskjöld Plaza

New York, NY 10017,

United States

Email: jbongaarts@popcouncil.org

\section{Sarah E.K. Bradley}

Department of Demography

University of California

2232 Piedmont Avenue

Berkeley, CA 94720

United States

Email: sekbradley@gmail.com

John B. Casterline

Professor of Sociology

Ohio State University

238 Townshend Hall

1885 Neil Avenue

Columbus, Ohio 43210,

United States

Email: casterline.10@osu.edu 
James Ciera

African Institute for Development Policy

Suite \# 29, Royal Offices, Mogotio Road

P. O. Box 14688-00800

Westlands, Nairobi,

Kenya

Email: james.ciera@afidep.org

\section{John Cleland}

London School of Hygiene and Tropical Medicine

Department of Population Studies

Keppel Street

London WC1E 7HT

United Kingdom

Email: john.cleland@1shtm.ac.uk

Lester Coutinho*

Packard Foundation

343 Second Street

Los Altos CA 94022

USA

Email: 1coutinho@packard.org

\section{Alex Chika Ezeh}

African Population and Health Research Center

APHRC Campus, 2nd Floor

Manga Close, Off Kirawa Rd

P.O. Box 10787-00100

Nairobi, Kenya

Email: aezeh@aphrc.org

\section{Debbie Gachuhi}

Johns Hopkins University

Center for Communication Programmes

PO Box 21529

Nairobi, 00505

Kenya

Email: dgachuhi@tupange.or.ke

\section{Sandra Garcia}

Research, Monitoring and Evaluation Unit The Susan Thompson Buffett Foundation 3555 Farnum Street, Suite 222

Omaha, Nebraska 68131

United States

Email: sgarcia@stbfoundation.org
Jill Hagey

Population Reference Bureau

1875 Connecticut Avenue, NW

Suite 520

Washington, DC 20009-5728

United States

Email: jhagey@prb.org

\section{Sarah Harbison}

US Agency for International Development

Office of Population and Reproductive Health

1300 Pennsylvania Ave, NW

Washington, DC 20523

United States

Email: sharbison@usaid.gov

\section{Anrudh K. Jain}

The Population Council

One Dag Hammarskjöld Plaza

New York, NY 10017,

United States

Email: ajain@popcouncil.org

\section{Shireen J. Jejeebhoy}

The Population Council

Zone 5-A

India Habitat Centre, Lodi Road

New Delhi 110003

India

Email: sjejeebhoy@popcouncil.org

Vladimira Kantorova

Population Division, United Nations

34 West 120th Street, Apt.2

New York, NY 10027

United States

Email: kantorova@un.org

\section{Jerusha Karuthiru}

USAID Kenya

Office of Population and Health

P.O Box 62900622

Village Market

Nairobi

Kenya

Email: jkaruthiru@usaid.gov 


\section{Ejazuddin Khan}

The Population Council

Zone 5-A

India Habitat Centre, Lodi Road

New Delhi 110003

India

Email: mekhan@popcouncil.org

\section{David Kline}

Research, Monitoring and Evaluation Unit

The Susan Thompson Buffett Foundation

222 Kiewit Plaza

Omaha, Nebraska 68131

United States

Email: dkline@stbfoundation.org

\section{Paul Kuria}

Programs and Research

National Gender and Equality Commission

P.O. box 32149, code 00600

Nairobi

Kenya

Email:pkkush05@yahoo.com

\section{Elizabeth Leahy Madsen}

Futures Group

1 Thomas Circle NW, Suite 200

Washington, DC 20005

United States

Email: eleahymadsen@futuresgroup.com

\section{Sheila N. Macharia}

USAID Kenya

Office of Population and Health

P.O Box 62900621

Village Market, Nairobi

Kenya

Email: smacharia@usaid.gov

\section{Kazuyo Machiyama}

London School Of Hygiene \& Tropical Medicine

Department of Population Studies

London WC1E 7HT,

United Kingdom

Email: kazuyomachiyama@gmail.com

\section{Supriya Madhavan}

Johns Hopkins Bloomberg School of Public Health 615 North Wolfe Street

Baltimore, MD 21205

United States

Email: sumadhav@jhsph.edu

\section{Shawn Malarcher}

US Agency for International Development

Office of Population and Reproductive Health

1300 Pennsylvania Ave, NW

Washington, DC 20523

United States

Email: smalarcher@usaid.gov

\section{Paul Monet}

International Union for the Scientific Study

of Population (IUSSP)

3-5 rue Nicolas

75980 Paris cedex 20

France

Email: monet@iussp.org

Joyce Mumah

African Population and Health Research Center

APHRC Campus, 2nd Floor

Manga Close, Off Kirawa Rd

P.O. Box 10787-00100

Nairobi, Kenya

Email: jmumah@aphrc.org

Joyce Ombeva

Population Council

P.O. Box 17643

Nairobi

Kenya

Email: jombeva@popcouncil.org

James F. Phillips*

Heilbrunn Department of Population and Family

Health

Mailman School of Public Health

Columbia University

60 Haven Avenue, Suite B-2

New York, NY 10032,

United States

Email: james.phillips@ columbia.edu 


\section{Clémentine Rossier}

Institut Supérieur des Sciences de la Population,

Université de Ouagadougou, 03 BP 7118

Ouagadougou 03,

Burkina Faso

Email: clementine.rossier@ined.fr

\section{Karampreet Sachathep}

Johns Hopkins Bloomberg School of Public Health

615 N Wolfe St

Baltimore, Maryland 21205

United States

Email: ksachath@jhsph.edu

\section{John Michael Ian Salas}

University of California, Irvine

2311 Verano Place

Irvine, CA 92617

United States

Email: jmisalas@gmail.com

\section{K.G. Santhya}

Population Council

Zone 5a, Ground Floor

India Habitat Centre, Lodi Road

New Delhi 110003

India

Email: kgsanthya@popcouncil.org

\section{Gilda Sedgh}

Guttmacher Institute

125 Maiden Lane

7th Floor

New York, NY 10038

United States

Email: gsedgh@guttmacher.org

\section{Leigh Senderowicz}

Institut Supérieur des Sciences de la Population,

Université de Ouagadougou

ISSP/UO

03 BP 7118 Ouagadougou 03

Burkina Faso

Email: leigh.senderowicz@gmail.com

\section{Iqbal H. Shah}

Chemin de Malvand, 12 C

1292 Chambesy

Switzerland

Email: IqbalH.Shah@gmail.com

Estelle Monique Sidze*

African Population and Health Research Center

APHRC Campus, 2nd Floor

Manga Close, Off Kirawa Rd

P.O. Box 10787-00100

Nairobi, Kenya

Email: esidze@aphrc.org

\author{
Ajay Singh \\ Population Council, India \\ G-180/F1 (Second Floor) \\ Dilshad Colony \\ Delhi 110095 \\ India
}

Email: krsajay@yahoo.co.in

Catriona Towriss

London School of Hygiene and Tropical Medicine

Keppel Street

London WC1E 7HT

United Kingdom

Email: catriona.towriss@1shtm.ac.uk

\section{Eunice William}

African Institute for Development Policy

Suite \# 29, Royal Offices, Mogotio Road

P. O. Box 14688-00800

Westlands, Nairobi,

Kenya

Email: eunice.mueni@afidep.org

Eliya Msiyaphazi Zulu

African Institute for Development Policy

Suite \# 29, Royal Offices, Mogotio Road

P. O. Box 14688-00800

Westlands, Nairobi,

Kenya

Email: eliya.zulu@afidep.org

*Unable to attend. 